\title{
Molecular Diversity Analysis in Fennel (Foeniculum vulgare Mill) Genotypes and its Implications for Conservation and Crop Breeding
}

\author{
Sharda Choudhary", Radheshyam Sharma, R.S. Meena and Arvind Kumar Verma
}

ICAR-National Research Centre on Seed Spices, Ajmer 305-206 (Rajasthan), India

*Corresponding author

\begin{tabular}{|l|}
\hline Ke y w o r d s \\
Fennel, ISSR, \\
Molecular diversity, \\
Molecular marker, \\
Polymorphism, \\
RAPD \\
\hline Article Info \\
\hline Accepted: \\
07 February 2018 \\
Available Online: \\
10 March 2018 \\
\hline
\end{tabular}

\section{A B S T R A C T}

Seed spices are most valuable crops having a good export potential to boost national economy. Among all seed spices, fennel has their prime importance in medicinal and nationwide market. This crop is highly variable and rich in molecular variability. Two DNA based molecular marker techniques viz., Random Amplified Polymorphic DNA (RAPD) and inter-simple sequence repeat (ISSR), were used to study the molecular diversity among 17 fennel genotypes. A total of 26 polymorphic primers (16 random and 10 ISSR) were used. Amplification of genomic DNA of 17 genotypes, using RAPD analysis, yielded 79 fragments, in which $58(73.41 \%)$ were polymorphic. The 10 ISSR primers produced 59 bands across 17 genotypes, of which $51(86.44 \%)$ were polymorphic. The similarity coefficient ranged from 0.34 to 0.76 and 0.36 to 0.87 . Based on the similarity matrix data dendrogram were prepared using UPGMA method. Genotypes were also classified into groups and several subgroups, respectively. Principal Coordinate Analysis (PCA) confirmed the separation of fennel genotypes into groups comparable to those from UPGMA analysis. The high rate of polymorphic lines generated by RAPD and ISSR markers indicated that the method is efficient to analyze molecular diversity in fennel genotypes and that the molecular divergence can be used to establish consistent heterotic groups between fennel genotypes. Hence, molecular markers proud to be, superior in assessing differences among genetically very similar genotypes and efficiently utilized in plant breeding programme for improvement of crops.

\section{Introduction}

India is known as the "'Land of Spices" and largest producer, consumer and exporter of seed spices and their products in the world. Fennel (Foeniculum vulgare Mill), $2 \mathrm{n}=22$ an important open cross-pollinated crop, belong to family Apiaceae and is mainly grown for seeds. It is also used in folk medicine for its balasimic, cardiotonic, digestive, lactogogue and tonic properties (Saleha, 2011;
Saravanaperumal and Terza, 2012; Choudhary et al., 2017). Fennel seeds contain essential oil which has a valuable antioxidant, antibacterial, anticancer and antifungal activity (El-Awadi and Hassan, 2010). In India fennel is cultivated covering a total area of about 76000 ha with annual production of 129350 tonnes (DASD, 205-16). The importance of fennel was recognized long back due to its medicinal values and export potential as spices however it is remain 
neglected for long time towards improvement on its productivity and quality. With change to sophisticate life style, the value added, quality form of seed spices have become the thrust area for introduction of new produces. The main constraint for the production of value added products are lack of sufficient number of improved varieties having high volatile oil, low crude fibre, high soluble sugars and high seed yield. In the last few years, the interest for a possible industrial use of fennel is growing. Recently, fennel has become appoint of attraction for main international seed companies, which have improved research breeding programs.

Being an open cross-pollinated crop this crop has the abundant molecular variability and tremendous scope for development of improved varieties and characterization of germplasm. The methods based on morphological features are commonly used but they not always allow the most accurate information due to genotypes-environment interaction; on the contrary it is well reported that molecular methods overcome these problems.

Since not much molecular information is available in literature for fennel crop using molecular markers, thus RAPD and ISSR marker have been used with success to identify and determine relationships at the species, population and cultivar levels in many plant species, including several aromatic and medicinal plants (Haouari and Ferchichi, 2008).

These methods are widely applicable because they are rapid, inexpensive, require small amounts of template DNA and, unlike SSR markers, do not require prior designing of primer sequences (Godwin et al., 1997). RAPD and ISSR markers have been efficiently used for the study of molecular diversity in various seed spice crops like cumin, coriander and fenugreek (Choudhary et al., 2013; 2015; 2017, Singh et al., 2012).

The genetic variability and divergence present in the materials is an important tool for any breeding programme. The assessment of variation would provide us a correct picture of the extent of variation, further helping us to improve the genotypes for biotic and abiotic stresses. The main objective of this study was to characterize the fennel genotypes using morphological and molecular markers in order to evaluate the genetic diversity and relationships among genotypes lines.

\section{Materials and Methods}

\section{Plant materials}

Seventeen (17) diverse fennel genotypes developed from seven different geographical regions of the India (Table 1). The seeds were procured from Gene Bank, ICAR-National Research Centre on Seed Spices, Tabiji, Ajmer (Rajasthan), India. Seeds were grown in pots and kept in seed germinator with controlled conditions after 20 days of growth; leaves were cut and frozen in liquid nitrogen for DNA extraction. The present study was conducted in Biotechnology Laboratory at ICAR-National Research Centre on Seed Spices, Tabiji, Ajmer (Rajasthan), India.

\section{DNA extraction}

Leaves were ground in liquid nitrogen to a fine powder with chilled mortar and pestle. Genomic DNA was extracted using modified method of Doyle and Doyle (1990) Cetyl Trimethyl Ammonium Bromide (CTAB) method. The quantity and quality of DNA was determined by electrophoresis on $0.8 \%$ agarose gel as per Choudhary et al., (2016). DNA samples were diluted to $50 \mathrm{ng} \mu \mathrm{l}-1$ for Polymerase Chain Reaction (PCR) amplification. 


\section{RAPD and ISSR-PCR analysis}

RAPD-PCR amplification was performed using 40 random decamer primers obtained from IDT, India. Out of these 40 primers only sixteen (16) primers produced reproducible and scorable amplifications and chosen for further studies (Table 3). In ISSR-PCR analysis, only 10 primers were selected for further analysis out of 20 ISSR primers obtained from IDT, India. PCR amplifications for RAPD and ISSR were performed in $20 \mu \mathrm{l}$ volume containing $2 \mu \mathrm{dNTP}(250 \mu \mathrm{M}$ each dNTP), $1 \mu 1$ primer (30 ng $\mu \mathrm{l}-1), 1 \mu \mathrm{l}$ template DNA (50 ng $\mu \mathrm{l}-1$ ), $2.5 \mu \mathrm{l}$ reaction buffer [(10x) $10 \mathrm{mM}$ Tris-Cl pH 9.0, $50 \mathrm{mM} \mathrm{KCl]}$, $0.3 \mu \mathrm{l}$ Taq DNA polymerase [(5 U $\mu \mathrm{l}-1)$ SRL, India], $2 \mu \mathrm{MgCl} 2(25 \mathrm{mM})$, and $11.2 \mu \mathrm{l}$ deionized water. PCR reactions were performed with DNA thermal cycler (Bio Rad $\mathrm{C} 1000^{\mathrm{TM}}$ ). Amplification conditions were as follows: an initial denaturation at $94^{\circ} \mathrm{C}$ for 5 min followed by 1 min denaturation at $94^{\circ} \mathrm{C}$ for 36 cycles for RAPD and ISSR, respectively and $1 \mathrm{~min}$ at annealing temperature $\left(36^{\circ} \mathrm{C}\right.$ for RAPD; for ISSR, $22^{\circ} \mathrm{C}$ to $53^{\circ} \mathrm{C}$ it depends upon the primer), $2 \mathrm{~min}$ polymerization at $72^{\circ} \mathrm{C}$ and $2 \mathrm{~min}$ final extension at $72^{\circ} \mathrm{C}$. After the completion of amplification, $2 \mu \mathrm{l}$ of gel loading dye (SRL) was added to each sample and $20 \mu \mathrm{l}$ volume was resolved on 1.5 and $2.0 \%(\mathrm{w} / \mathrm{v})$ agarose gel for RAPD and ISSR, respectively in $1 \times$ Tris-Borate-Ethylene Diamine Tetra Acetic Acid (TBE) buffer, gels were stained with ethidium bromide. The sizes of amplified DNA fragments were estimated by comprising them with standard molecular size markers. The gels were visualized under UV using gel documentation system (Gelvision, DC, India). DNA amplifications with each RAPD and ISSR primers were repeated at least three times to ensure reproducibility. The bands were considered reproducible and scorable only after observing and comparing them in three separate amplifications for each primer.
Clear and intense bands were scored while faint bands against smear background were not considered for further analysis.

\section{Scoring and data analysis}

DNA fingerprints were scored for the presence (1) or absence (0) of bands for various molecular weight and sizes in the form of binary matrix. Initially, the potential of both the markers for estimating molecular variability of fennel genotypes was examined by measuring the marker information through counting of bands. Primer banding patterns such as number of total bands (TB), number of polymorphic bands (PB) and percentage of polymorphic bands (PPB) were obtained. To analyze the suitability of both the markers for evaluation of molecular profiles of fennel genotypes, the performance of the markers was measured using two basic parameters: polymorphic information content (PIC), marker index (MI). The PIC value for each locus was calculated using formula (RoldanRuiz et al., 2000); PICi = 2fi (1 - fi), Where $\mathrm{PIC} i$ is the polymorphic information content of the locus $i, f i$ is the frequency of the amplified fragments and 1-fi is the frequency of non-amplified fragments. The frequency was calculated as the ratio between the number of amplified fragments at each locus and the total number of accessions (excluding missing data). The PIC of each primer was calculated using average PIC value from all loci of each primer. Effective multiplex ratio was calculated using formula; EMR (effective multiplex ratio) $=\mathrm{n} 9 \mathrm{~b}$, where $\mathrm{n}$ is the average number of fragments amplified by accession to a specific system marker (multiplex ratio) and $b$ is estimated from the number of polymorphic loci $(\mathrm{PB})$ and the number of nonpolymorphic loci (MB); $b=\mathrm{PB} /(\mathrm{PB}+\mathrm{MB})$. Marker index for both the markers was calculated to characterize the capacity of each primer to detect polymorphic loci among the genotypes. Marker index for each primer was 
calculated as a product of polymorphic information content and effective multiplex ratio (Varshney et al., 2007); $\mathrm{MI}=\mathrm{EMR} \mathrm{X}$ PIC. Data were analyzed to obtain Jaccard's coefficients (Jaccard, 1908) among the isolates by using NTSYS-pc version 2.02e (Rohlf, 1998). The data matrix of both markers was then converted into molecular similarity matrix using Jaccard coefficient (Jaccard, 1908) in SPSS 17.0 (SPSS Inc.) and NTSYSPC $2.02 \mathrm{j}$ (Rohlf, 1998). The data matrix was used to determine the molecular diversity, molecular differentiation and gene flow. Eigenvalues and eigenvectors were calculated by the Eigen program using a correlation matrix as input from NTSYS-pc. The cophenetic correlation was calculated to find the degree of association between the original similarity matrix and the tree matrix in both morphological and molecular analyses. Using the Mantel test (Mantel, 1967), a comparison between both methods was performed for RAPD and ISSR data sets. Using the same software, PCA was also carried out to identify any genetic association among the genotypes. Further, principal component analysis (PCA) was performed to highlight the resolving power of the ordination based on similarity coefficient of data realized from RAPD and ISSR average similarity indices using SPSS statistics 17.0 software (SPSS Inc.).

\section{Results and Discussion}

\section{RAPD band pattern}

Information on molecular diversity and relationship among individuals, population, plant varieties and species are important to plant breeders for the improvement of crop plants. Molecular diversity studies can identify alleles that might affect the ability of the organism to survive in its existing habitat, or might enable it to survive in more diverse habitats. This knowledge is valuable for germplasm conservation, individual, population, variety or breed identification and molecular improvement (Duran et al., 2009). Various types of markers such as morphological, biochemical and molecular markers are used for this purpose (Barwar et al., 2008). Forty RAPD primers having 50\% or more GC content were used for the present investigation. Out of them only sixteen primers were satisfactory and reproducible. The reason for the non-amplifications of the other 24 primers could not be explained. Probably the sample DNA did not have any binding site for the primers. A similar non amplification of decamer primers was reported by, Sosinski and Douches (1996) and Mattagajasingh et al., (2006), in different plant species. The amplification pattern is shown in Figure 1 and the details of the RAPD analysis in Table 3. All these 16 primers resulted in the amplification of 79 amplified bands from which 58 were polymorphic and showed $73.41 \%$ polymorphism indicating the presence of high degree of molecular variation in the studied fennel varieties. The DNA amplicon size and polymorphism generated among various genotypes of fennel using RAPD primers are presented in Table 3. The total number of bands observed for every primer was recorded separately and polymorphic bands were checked subsequently. The total number of amplified bands varied between 2 (primer OPB-06, OPC-04 and OPC-05) and 9 (primer OPB-07) with an average of 4.9 bands per primer. The polymorphism of all 17 fennel genotype were $73.41 \%$ and the overall size of PCR amplified products ranged between $180 \mathrm{bp}$ to $2900 \mathrm{bp}$. Similar to the present finding Choudhary et al., (2013) obtained high level of polymorphism of 57.66 per cent among Indian fenugreek varieties. Based on RAPD similarity matrix data, the value of similarity coefficient ranged from 0.48 to 0.97 (Table 5). The average similarity across all the genotypes was found out to be 0.72 showing that genotype were polymorphic genetically. 
The RAPD cluster tree analysis of 17 fennel genotypes showed that they were mainly divided into main three clusters (Figure 3). Cluster I contain eight genotypes viz., RF-101, RF-205, RF-178, RF-145, RF-125, RF-143, RF-281 and AF-1.

These genotypes are developed from same climatic condition and having similar longitude and latitude. Among these eight genotypes AF-1 is out grouped from other due to minor difference between their places of origin. All genotypes were developed from SKRAU-Jobner, Jaipur except AF-1 which is developed at NRCSS-Ajmer.

Cluster II having five genotypes with diverse origin and different geographical distribution, includes, Rajendra-saurabh, Azad-saunf-1, CO-1, Pant-madhurika and Hisar-swarup. Among all, Hisar-swarup is outgrouped from rest of all genotypes at a similarity coefficient of 0.65. Similarly, in cluster III four genotypes were present, all these were developed at SDAU-Jagudan, Gujarat having similar climatic condition and depicting to be originated from a single ancestors. The analysis gave 16 PCs, out of which the first 10 PCs contributed $97.495 \%$ of the total variability of the analyzed genotypes. The first 5 PCs accounted for $83.08 \%$ of the total variability; the first 3 accounted for $70.95 \%$ of the variance, in which maximum variability was contributed by the first component (38.16\%), followed by the second $(20.26 \%)$ and third (12.54\%) components. Based on Mantel Z-statistics (Mantel, 1967), the correlation coefficient (r) was estimated as 0.95. The $r$ value of 0.91 was considered a good fit of the UPGMA cluster pattern to RAPD data (Fig. 4).

\section{ISSR band pattern}

10 ISSR primers amplified 59 clear and scorable bands across 17 fennel genotypes, of which 51 were polymorphic (Table 4). The total number of bands observed for every primer was recorded separately and polymorphic percentage was calculated subsequently (Table 4). The total number of amplified bands varied between 2 (primerUBC-820) and 8 (primers-UBC-810, UBC814 and UBC-824) with an average of 5.9 per primer.

The polymorphism percentage ranged from as low as $50 \%$ (primer-UBC-821) to as high as $100 \%$ in six primers (Primer-UBC-810, UBC820, UBC-814, UBC-824, UBC-826 and UBC-827). Average polymorphism across all the 17 genotypes of fennel was found to be $86.44 \%$ showing abundant molecular diversity at the population level (Sun et al., 2004). Overall size of PCR amplified products ranged between $100 \mathrm{bp}$ to $1550 \mathrm{bp}$. PIC is a feature of a primer and, therefore, PIC values were calculated for all the primers. Maximum, minimum and average values of Polymorphism information content index (PIC) were found to be $0.66,0.00$ and 0.35 , respectively (Table 4). Since the average value of PIC (0.35) showed a good efficiency of the used primers in discrimination of the individuals. Although the low PIC value obtained by some IISR markers maybe only due to low number of IISR loci studied. Similar results have been reported by other workers (Pirseyedi et al., 2010; Soriano et al., 2011).

Marker index (MI) as a feature of marker diversity was also calculated for all the primers based on the PIC and polymorphic bands are showed in Table 4. MI value ranged from 0 to 5.28 with an average value 1.86. Highest MI (5.28) was observed with primer UBC-810 that generated 8 polymorphic fragments across all the 17 genotypes of fennel. Based on ISSR similarity matrix data, the value of similarity coefficient ranged from 0.39 to 0.96 (Table 6). 
Table.1 Details of fennel genotypes from different geographical regions of India for the study of molecular diversity

\begin{tabular}{|c|c|c|c|c|}
\hline $\begin{array}{l}\text { S. } \\
\text { No. }\end{array}$ & $\begin{array}{l}\text { Genotype } \\
\text { Code }\end{array}$ & Genotype & Geographical region & $\begin{array}{l}\text { Latitude and } \\
\text { Longitude }\end{array}$ \\
\hline 1. & $\mathrm{G}_{1}$ & GF-1 & SDAU-Jagudan (Guj.) & $23^{\circ} 51^{\prime} \mathrm{N}, 72^{\circ} 41^{\prime} \mathrm{E}$ \\
\hline 2. & $\mathrm{G}_{2}$ & GF-2 & SDAU-Jagudan (Guj.) & $23^{\circ} 51^{\prime} \mathrm{N}, 72^{\circ} 41^{\prime} \mathrm{E}$ \\
\hline 3 & $\mathrm{G}_{3}$ & GF-11 & SDAU-Jagudan (Guj.) & $23^{\circ} 51^{\prime} \mathrm{N}, 72^{\circ} 41^{\prime} \mathrm{E}$ \\
\hline 4 & $\mathrm{G}_{4}$ & $\mathrm{GF}-12$ & SDAU-Jagudan (Guj.) & $23^{\circ} 51^{\prime} \mathrm{N}, 72^{\circ} 41^{\prime} \mathrm{E}$ \\
\hline 5 & $\mathrm{G}_{5}$ & RF-101 & SKNRAU-Jobner (Raj.) & $26^{\circ} 97^{\prime} \mathrm{N}, 75^{\circ} 38^{\prime} \mathrm{E}$ \\
\hline 6 & $\mathrm{G}_{6}$ & $\mathrm{RF}-125$ & SKNRAU-Jobner (Raj.) & $26^{\circ} 97^{\prime} \mathrm{N}, 75^{\circ} 38^{\prime} \mathrm{E}$ \\
\hline 7 & $\mathrm{G}_{7}$ & $\mathrm{RF}-143$ & SKNRAU-Jobner (Raj.) & $26^{\circ} 97^{\prime} \mathrm{N}, 75^{\circ} 38^{\prime} \mathrm{E}$ \\
\hline 8 & $\mathrm{G}_{8}$ & RF-178 & SKNRAU-Jobner (Raj.) & $26^{\circ} 97^{\prime} \mathrm{N}, 75^{\circ} 38^{\prime} \mathrm{E}$ \\
\hline 9 & $\mathrm{G}_{9}$ & $\mathrm{RF}-281$ & SKNRAU-Jobner (Raj.) & $26^{\circ} 97^{\prime} \mathrm{N}, 75^{\circ} 38^{\prime} \mathrm{E}$ \\
\hline 10 & $\mathrm{G}_{10}$ & $\mathrm{RF}-145$ & SKNRAU-Jobner (Raj.) & $26^{\circ} 97^{\prime} \mathrm{N}, 75^{\circ} 38^{\prime} \mathrm{E}$ \\
\hline 11 & $\mathrm{G}_{11}$ & RF-205 & SKNRAU-Jobner (Raj.) & $26^{\circ} 97^{\prime} \mathrm{N}, 75^{\circ} 38^{\prime} \mathrm{E}$ \\
\hline 12 & $\mathrm{G}_{12}$ & Rajendra-Saurabh & RAU-Dholli (Bhihar) & $25^{\circ} 85^{\prime} \mathrm{N}, 85^{\circ} 78^{\prime} \mathrm{E}$ \\
\hline 13 & $\mathrm{G}_{13}$ & Azad-Saunf-1 & CSAUAT-Kanpur (UP) & $26^{\circ} 50^{\prime} \mathrm{N}, 80^{\circ} 30^{\prime} \mathrm{E}$ \\
\hline 14 & $\mathrm{G}_{14}$ & $\mathrm{CO}-1$ & TAU-Coimbatore (TN) & $11^{\circ} 01^{\prime} \mathrm{N}, 76^{\circ} 97^{\prime} \mathrm{E}$ \\
\hline 15 & $\mathrm{G}_{15}$ & Pant-Madhuricka & GBPAUT-Pantnagar (UK) & $28^{\circ} 97^{\prime} \mathrm{N}, 79^{\circ} 41^{\prime} \mathrm{E}$ \\
\hline 16 & $\mathrm{G}_{16}$ & $\mathrm{AF}-1$ & NRCSS-Ajmer (Raj.) & $26^{\circ} 45^{\prime} \mathrm{N}, 74^{\circ} 64^{\prime} \mathrm{E}$ \\
\hline 17 & $\mathrm{G}_{17}$ & Hisar-Swarup & CCHAU-Hisar (HR) & $29^{\circ} 19^{\prime} \mathrm{N}, 76^{\circ} 23^{\prime} \mathrm{E}$ \\
\hline
\end{tabular}

Table.2 Unique/genotype specific bands as detected by 3 RAPD and 1 ISSR primers in 17 genotypes of fennel

\begin{tabular}{|l|l|l|l|}
\hline RAPD Primers & Genotype & No. of Unique band & Size of Band (bp) \\
\hline OPB-07 & Pant-madurika & 1 & 1850 \\
\hline OPB-11 & Co-1 & 1 & 210 \\
\hline ISSR primer & Hisar-swarup & 1 & 1550 \\
\hline UBC-810 & & 3 & \\
\hline Total & & &
\end{tabular}


Table.3 Performance of 16 RAPD primers in the molecular diversity analysis of fennel genotypes

\begin{tabular}{|c|c|c|c|c|c|c|c|c|c|c|c|c|}
\hline Primer* & Sequence $5^{\prime}$ to $3^{\prime}$ & G:C (\%) & Size (bp) & TGA & TB & PB & MB & $\mathbf{P P}$ & PIC & B & EMR & MI \\
\hline OPA-01 & AGGCCCTTC & 70 & $200-1400$ & 17 & 6 & 5 & 1.00 & 83.33 & 0.74 & 0.83 & 4.15 & 3.07 \\
\hline OPB-06 & TGCTCTGCCC & 70 & $300-700$ & 17 & 2 & 1 & 1.00 & 50 & 0.17 & 1.0 & 1.00 & 0.17 \\
\hline OPB-07 & GGTGACGCAG & 70 & $80-1850$ & 17 & 9 & 9 & 0.00 & 100 & 0.85 & 1.0 & 9.00 & 7.65 \\
\hline OPB-11 & GTAGACCCGT & 60 & $170-1200$ & 17 & 4 & 4 & 0.00 & 100 & 0.69 & 1.0 & 4.00 & 2.76 \\
\hline OPD-12 & CACCGTATCC & 60 & $250-1000$ & 17 & 5 & 4 & 1.00 & 80 & 0.74 & 1.25 & 5.00 & 3.70 \\
\hline OPE-03 & CCAGATGCAC & 60 & $300-800$ & 17 & 2 & 2 & 0.00 & 100 & 0.32 & 1.0 & 2.00 & 0.64 \\
\hline OPC-01 & AACCCGGGAA & 60 & $150-1200$ & 17 & 6 & 3 & 3.00 & 50 & 0.79 & 2.0 & 6.00 & 4.74 \\
\hline OPC-02 & ССТСТАGACC & 60 & $200-1600$ & 17 & 7 & 5 & 2.00 & 71.42 & 0.82 & 0.71 & 3.55 & 2.91 \\
\hline OPC-03 & CCGAACACGG & 70 & $250-1600$ & 17 & 4 & 3 & 1.00 & 75 & 0.67 & 0.75 & 2.25 & 1.50 \\
\hline OPC-04 & GTAGCACTCC & 60 & $400-800$ & 17 & 2 & 1 & 1.00 & 50 & 0.37 & 0.5 & 0.5 & 0.18 \\
\hline OPC-05 & CTGATACGCC & 60 & $300-600$ & 17 & 2 & 1 & 1.00 & 50 & 0.35 & 0.5 & 0.5 & 0.17 \\
\hline OPC-06 & GTGGGCTGAC & 70 & $300-1100$ & 17 & 4 & 4 & 0.00 & 100 & 0.62 & 1.0 & 4.00 & 2.48 \\
\hline OP7-07 & GTCCATGCCA & 60 & $400-1700$ & 17 & 6 & 3 & 3.00 & 50 & 0.73 & 0.5 & 1.5 & 1.09 \\
\hline OPC-08 & ACATCGCCCA & 60 & $200-1800$ & 17 & 8 & 8 & 0.00 & 100 & 0.83 & 1.0 & 8.00 & 6.64 \\
\hline OPC-12 & AAGGGCGAGT & 60 & $200-1600$ & 17 & 5 & 2 & 3.00 & 40 & 0.57 & 0.4 & 0.8 & 0.45 \\
\hline OPC-16 & CCAAGCTGCC & 70 & $80-1050$ & 17 & 7 & 3 & 4.00 & 42.85 & 0.83 & 0.42 & 1.68 & 1.39 \\
\hline \multicolumn{2}{|c|}{ Total A verage } & & & & 79 & 58 & 73.41 & 74.53 & 0.63 & 0.44 & 3.37 & 2.47 \\
\hline
\end{tabular}

* Operon series code, TGA=Total Number of Genotype Amplified, TB=Total Number of bands, PB=Polymorphic bands, MB=Monomorpic bands, $\mathrm{PP}=\mathrm{Percent}$ polymorphism, PIC, EMR=Effective multiplex ratio, MI=Marker Index 
Table.4 Performance of 10 ISSR primers in the molecular diversity analysis of fennel genotypes

\begin{tabular}{|c|c|c|c|c|c|c|c|c|c|c|c|c|}
\hline Primer* & Sequence $5^{\prime}$ to $3^{\prime}$ & TM $\left({ }^{0} \mathrm{C}\right)$ & Size (bp) & TGA & TB & PB & MB & PP & PIC & B & EMR & MI \\
\hline UBC807 & $(\mathrm{AG})_{8} \mathrm{~T}$ & 45.5 & $150-1300$ & 17 & 6 & 4 & 2 & 66.66 & 0.36 & 0.66 & 2.40 & 0.86 \\
\hline UBC810 & $(\mathrm{GA})_{8} \mathrm{~T}$ & 44.0 & $100-1500$ & 17 & 8 & 8 & 0 & 100 & 0.66 & 1.00 & 8.00 & 5.28 \\
\hline UBC811 & $(\mathrm{GA})_{8} \mathrm{C}$ & 44.8 & $100-1150$ & 17 & 7 & 4 & 3 & 57.14 & 0.38 & 0.57 & 2.28 & 0.86 \\
\hline $\mathrm{UBC} 814$ & $(\mathrm{CT})_{8} \mathrm{~A}$ & 43.0 & $200-1200$ & 17 & 8 & 8 & 0 & 100 & 0.58 & 1.00 & 8.00 & 4.64 \\
\hline UBC816 & $(\mathrm{CA})_{8} \mathrm{~T}$ & 48.0 & $250-1000$ & 17 & 5 & 4 & 1 & 80.0 & 0.27 & 0.80 & 3.20 & 0.86 \\
\hline $\mathrm{UBC} 820$ & $(\mathrm{GT})_{8} \mathrm{C}$ & 50.0 & $300-500$ & 17 & 2 & 2 & 0 & 100 & 0.53 & 1.00 & 2.00 & 1.06 \\
\hline UBC821 & $(\mathrm{GT})_{8} \mathrm{G}$ & 49.0 & $300-1000$ & 17 & 4 & 2 & 2 & 50.0 & 0.00 & 0.5 & 1.00 & 0.00 \\
\hline $\mathrm{UBC} 824$ & $(\mathrm{TC})_{8} \mathrm{G}$ & 46.5 & $150-1550$ & 17 & 8 & 8 & 0 & 100 & 0.49 & 1.00 & 8.00 & 3.92 \\
\hline UBC826 & $(\mathrm{AC})_{8} \mathrm{C}$ & 50.0 & $180-1400$ & 17 & 7 & 7 & 0 & 100 & 0.00 & 1.00 & 7.00 & 0.00 \\
\hline UBC827 & $(\mathrm{AC})_{8} \mathrm{G}$ & 51.5 & $300-900$ & 17 & 4 & 4 & 0 & 100 & 0.30 & 1.00 & 4.00 & 1.2 \\
\hline \multicolumn{3}{|c|}{ Total Average } & & & 59 & 51 & 8 & 86.44 & 0.35 & 0.86 & 4.58 & 1.86 \\
\hline
\end{tabular}

TGA=Total Number of Genotype Amplified, TB=Total Number of bands, $\mathrm{PB}=$ Polymorphic bands, MB=Monomorpic bands, PP=Percent polymorphism, PIC, $\mathrm{EMR}=$ Effective multiplex ratio, $\mathrm{MI}=$ Marker Index

Table.5 Jaccard similarity matrix generated using UPGMA method with RAPD primers

\begin{tabular}{|c|c|c|c|c|c|c|c|c|c|c|c|c|c|c|c|c|c|}
\hline & 息 & 壳 & 공 & $\frac{7}{7}$ & $\frac{\bar{\sigma}}{\frac{1}{\alpha}}$ & בี & $\frac{\mathscr{m}}{\mathscr{I}}$ & $\frac{\infty}{\sqrt{2}}$ & $\begin{array}{l}\overrightarrow{0} \\
\text { ते } \\
\underline{x}\end{array}$ & $\frac{8}{1}$ & 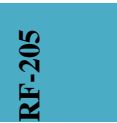 & 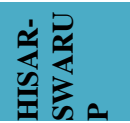 & 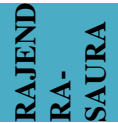 & 安至 & ঠ் & 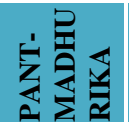 & $\frac{1}{4}$ \\
\hline GF-1 & 1.00 & & & & & & & & & & & & & & & & \\
\hline GF-2 & 1.00 & 1.00 & & & & & & & & & & & & & & & \\
\hline GF-11 & 0.75 & 0.75 & 1.00 & & & & & & & & & & & & & & \\
\hline GF-12 & 0.40 & 0.40 & 0.45 & 1.00 & & & & & & & & & & & & & \\
\hline RF-101 & 0.18 & 0.18 & 0.17 & 0.02 & 1.00 & & & & & & & & & & & & \\
\hline RF125 & 0.36 & 0.36 & 0.30 & 0.02 & 0.54 & 1.00 & & & & & & & & & & & \\
\hline RF-143 & 0.27 & 0.27 & 0.25 & 0.02 & 0.71 & 0.72 & 1.00 & & & & & & & & & & \\
\hline RF-178 & 0.20 & 0.20 & 0.18 & 0.02 & 0.79 & 0.64 & 0.68 & 1.00 & & & & & & & & & \\
\hline RF-281 & 0.29 & 0.29 & 0.24 & 0.02 & 0.68 & 0.76 & 0.96 & 0.65 & 1.00 & & & & & & & & \\
\hline RF-145 & 0.22 & 0.22 & 0.18 & 0.02 & 0.90 & 0.62 & 0.72 & 0.71 & 0.76 & 1.00 & & & & & & & \\
\hline RF-205 & 0.20 & 0.20 & 0.19 & 0.02 & 0.95 & 0.58 & 0.75 & 0.75 & 0.72 & 0.95 & 1.00 & & & & & & \\
\hline HISAR-SWARUP & 0.22 & 0.22 & 0.20 & 0.02 & 0.58 & 0.59 & 0.69 & 0.42 & 0.67 & 0.59 & 0.62 & 1.00 & & & & & \\
\hline Rajendra-saurabh & 0.31 & 0.31 & 0.33 & 0.27 & 0.16 & 0.23 & 0.29 & 0.18 & 0.28 & 0.18 & 0.18 & 0.29 & 1.00 & & & & \\
\hline AZAD-SAUNF-1 & 0.44 & 0.44 & 0.48 & 0.33 & 0.19 & 0.26 & 0.28 & 0.20 & 0.30 & 0.22 & 0.20 & 0.20 & 0.57 & 1.00 & & & \\
\hline $\mathrm{CO}-1$ & 0.46 & 0.46 & 0.50 & 0.30 & 0.17 & 0.23 & 0.27 & 0.18 & 0.27 & 0.19 & 0.19 & 0.23 & 0.56 & 0.68 & 1.00 & & \\
\hline Pant-Madhurika & 0.38 & 0.38 & 0.45 & 0.35 & 0.18 & 0.24 & 0.29 & 0.20 & 0.29 & 0.20 & 0.20 & 0.24 & 0.60 & 0.72 & 0.77 & 1.00 & \\
\hline AF-1 & 0.34 & 0.34 & 0.42 & 0.33 & 0.15 & 0.20 & 0.24 & 0.16 & 0.24 & 0.16 & 0.17 & 0.24 & 0.61 & 0.60 & 0.55 & 0.58 & 1.00 \\
\hline
\end{tabular}


Table.6 Jaccard similarity matrix generated using UPGMA method with ISSR primers

\begin{tabular}{|c|c|c|c|c|c|c|c|c|c|c|c|c|c|c|c|c|c|}
\hline & 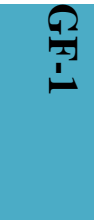 & $\begin{array}{l}\Omega \\
\mathbf{N}\end{array}$ & $\begin{array}{l}\Omega \\
0 \\
0\end{array}$ & $\begin{array}{l}\Omega \\
\stackrel{N}{N}\end{array}$ & 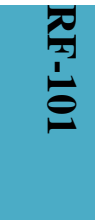 & $\begin{array}{l}\widetilde{D} \\
\text { U } \\
\text { U }\end{array}$ & $\begin{array}{l}\overrightarrow{0} \\
\vec{\omega} \\
\vec{\omega} \\
\vec{\omega}\end{array}$ & 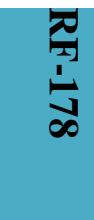 & $\begin{array}{l}\widetilde{D} \\
\dot{1} \\
\infty \\
0\end{array}$ & 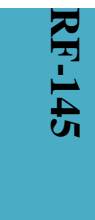 & ن̃ & $\begin{array}{ll}0 \\
0 \\
j\end{array}$ & $\sum_{0}^{2}$ & $\sum_{i}^{2}$ & 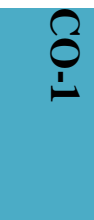 & $\sum_{3}^{Z}$ & $\vec{D}$ \\
\hline GF-1 & 1.00 & & & & & & & & & & & & & & & & \\
\hline GF-2 & 1.00 & 1.00 & & & & & & & & & & & & & & & \\
\hline GF-11 & 0.94 & 0.94 & 1.00 & & & & & & & & & & & & & & \\
\hline GF-12 & 0.71 & 0.71 & 0.77 & 1.00 & & & & & & & & & & & & & \\
\hline RF-101 & 0.74 & 0.74 & 0.81 & 0.84 & 1.00 & & & & & & & & & & & & \\
\hline RF125 & 0.97 & 0.97 & 0.97 & 0.74 & 0.77 & 1.00 & & & & & & & & & & & \\
\hline RF-143 & 0.84 & 0.84 & 0.90 & 0.74 & 0.84 & 0.87 & 1.00 & & & & & & & & & & \\
\hline RF-178 & 0.81 & 0.81 & 0.87 & 0.90 & 0.94 & 0.84 & 0.84 & 1.00 & & & & & & & & & \\
\hline RF-281 & 0.87 & 0.87 & 0.87 & 0.71 & 0.81 & 0.90 & 0.97 & 0.81 & 1.00 & & & & & & & & \\
\hline RF-145 & 0.81 & 0.81 & 0.81 & 0.77 & 0.94 & 0.84 & 0.84 & 0.87 & 0.87 & 1.00 & & & & & & & \\
\hline RF-205 & 0.77 & 0.77 & 0.84 & 0.81 & 0.97 & 0.81 & 0.87 & 0.90 & 0.84 & 0.97 & 1.00 & & & & & & \\
\hline HISAR-SWARUP & 0.77 & 0.77 & 0.84 & 0.74 & 0.77 & 0.81 & 0.87 & 0.71 & 0.84 & 0.77 & 0.81 & 1.00 & & & & & \\
\hline Rajendra-saurabh & 0.55 & 0.55 & 0.61 & 0.58 & 0.48 & 0.58 & 0.65 & 0.55 & 0.61 & 0.48 & 0.52 & 0.65 & 1.00 & & & & \\
\hline AZAD-SAUNF-1 & 0.52 & 0.52 & 0.52 & 0.42 & 0.39 & 0.48 & 0.55 & 0.45 & 0.52 & 0.39 & 0.42 & 0.42 & 0.77 & 1.00 & & & \\
\hline $\mathrm{CO}-1$ & 0.52 & 0.52 & 0.52 & 0.42 & 0.39 & 0.48 & 0.55 & 0.45 & 0.52 & 0.39 & 0.42 & 0.48 & 0.77 & 0.87 & 1.00 & & \\
\hline Pant-Madhurika & 0.52 & 0.52 & 0.58 & 0.48 & 0.45 & 0.55 & 0.61 & 0.52 & 0.58 & 0.45 & 0.48 & 0.55 & 0.84 & 0.87 & 0.94 & 1.00 & \\
\hline AF-1 & 0.42 & 0.42 & 0.48 & 0.45 & 0.35 & 0.45 & 0.52 & 0.42 & 0.48 & 0.35 & 0.39 & 0.52 & 0.81 & 0.65 & 0.71 & 0.77 & 1.0 \\
\hline
\end{tabular}




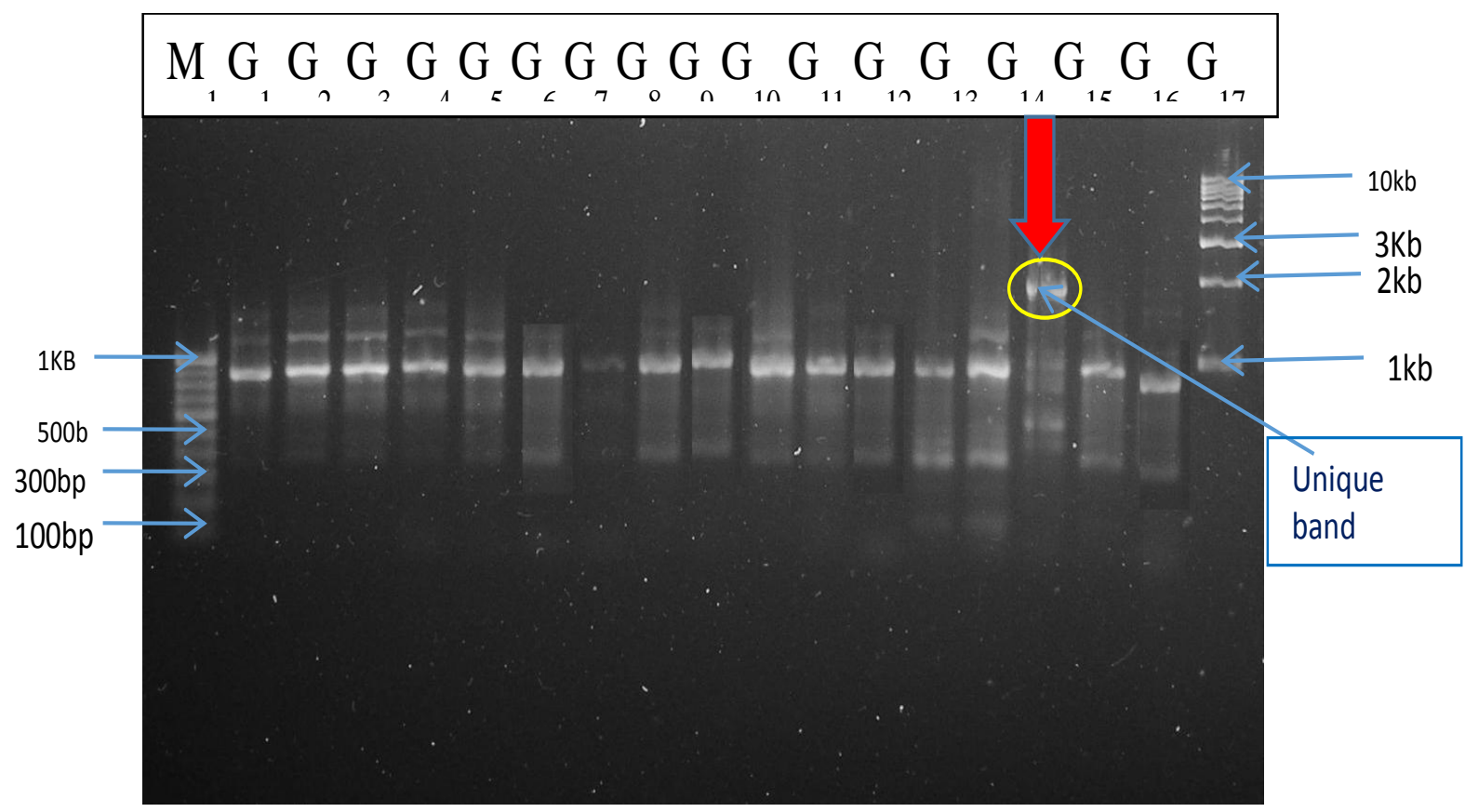

Figure 1. RAPD banding pattern generated through primer OPB-07 (M1=100 bp DNA ladder; M2=1kb DNA ladder, G1-G17 are code of different genotypes as listed in Table 1). Arrows indicate putative genotype specific bands.

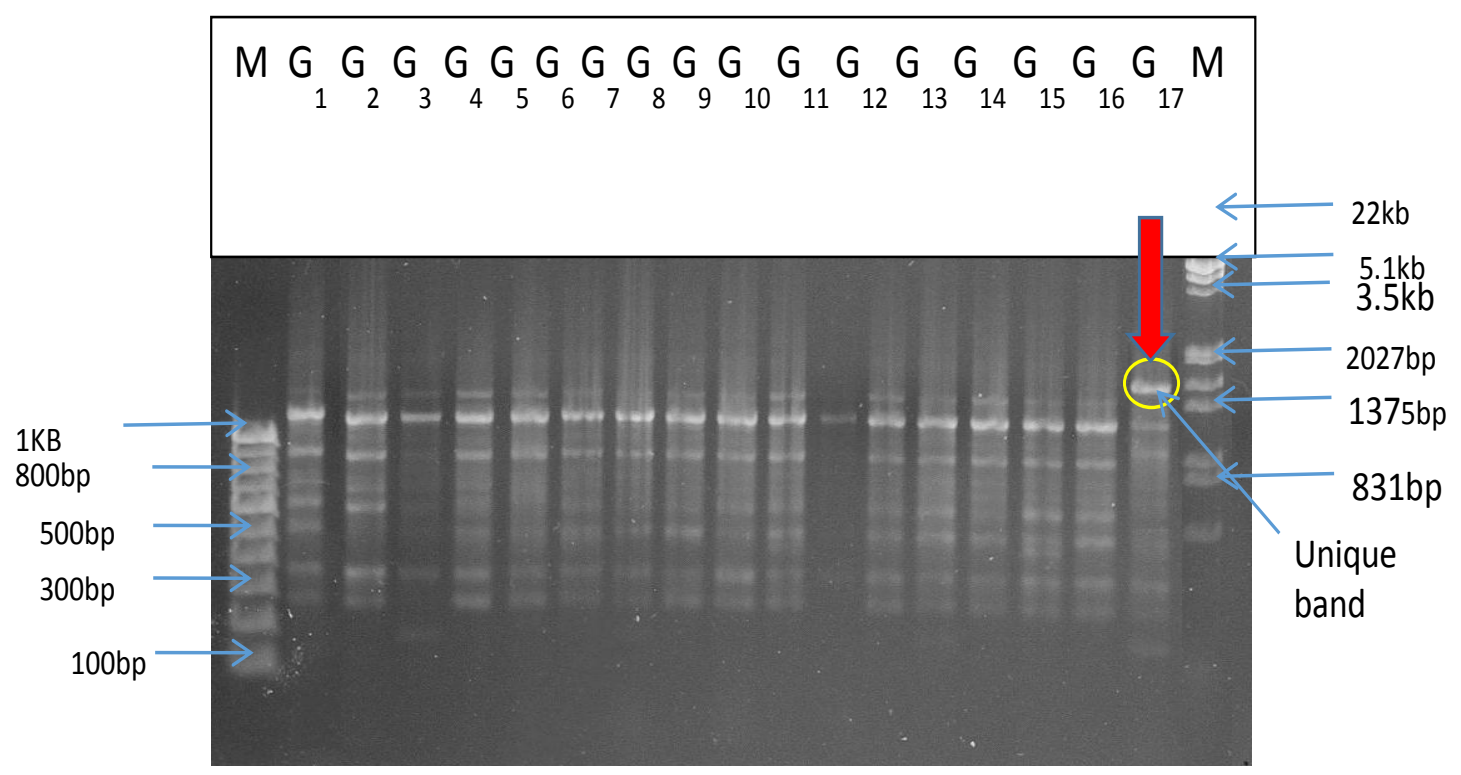

Figure 2. ISSR banding pattern generated through primer UBC-810 (M1=100 bp DNA ladder; M2= Lambda DNA/EcoRI/HindIII double digest, G1-G17 are code of different genotypes as listed in Table 1. Arrows indicate putative genotype specific bands 
Fig.3 Dandrogram constructed with UPGMA clustering method of 17 genotypes of Fennel using RAPD primers

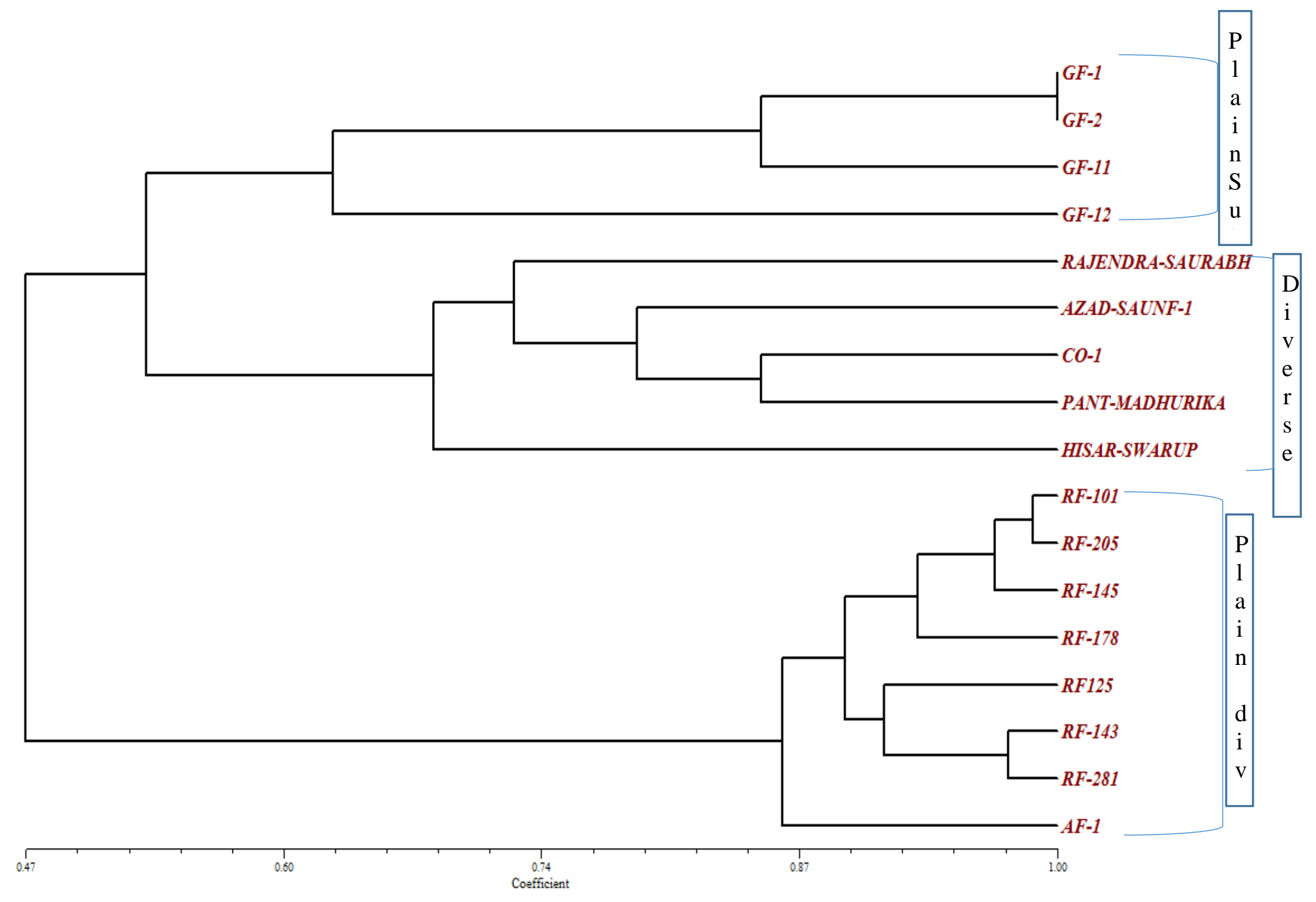


Int.J.Curr.Microbiol.App.Sci (2018) 7(3): 794-809

Fig.4 Two and three dimensional PCA analysis using RAPD markers
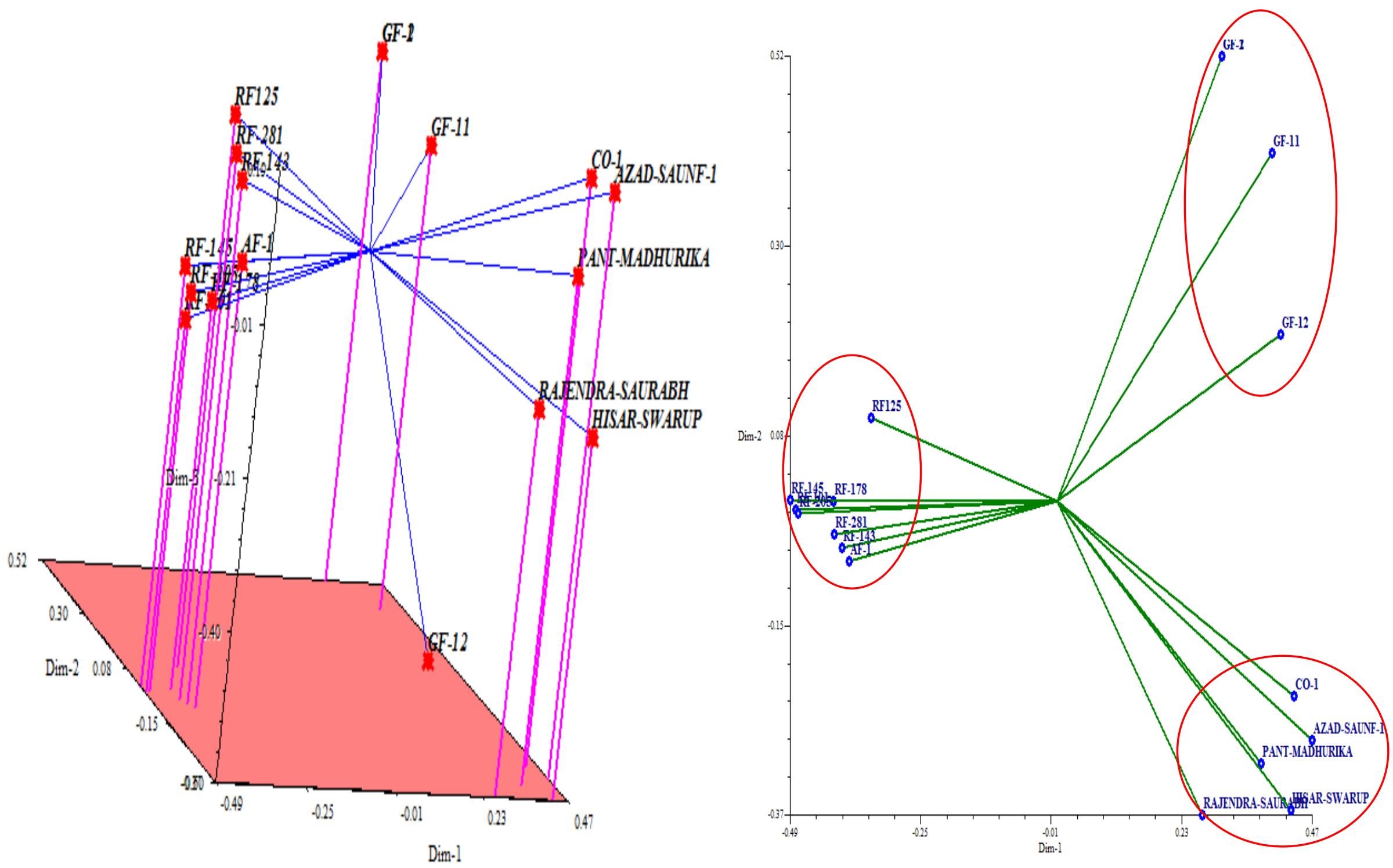
Fig.5 Dandrogram constructed with UPGMA clustering method of 17 genotypes of Fennel using ISSR primers

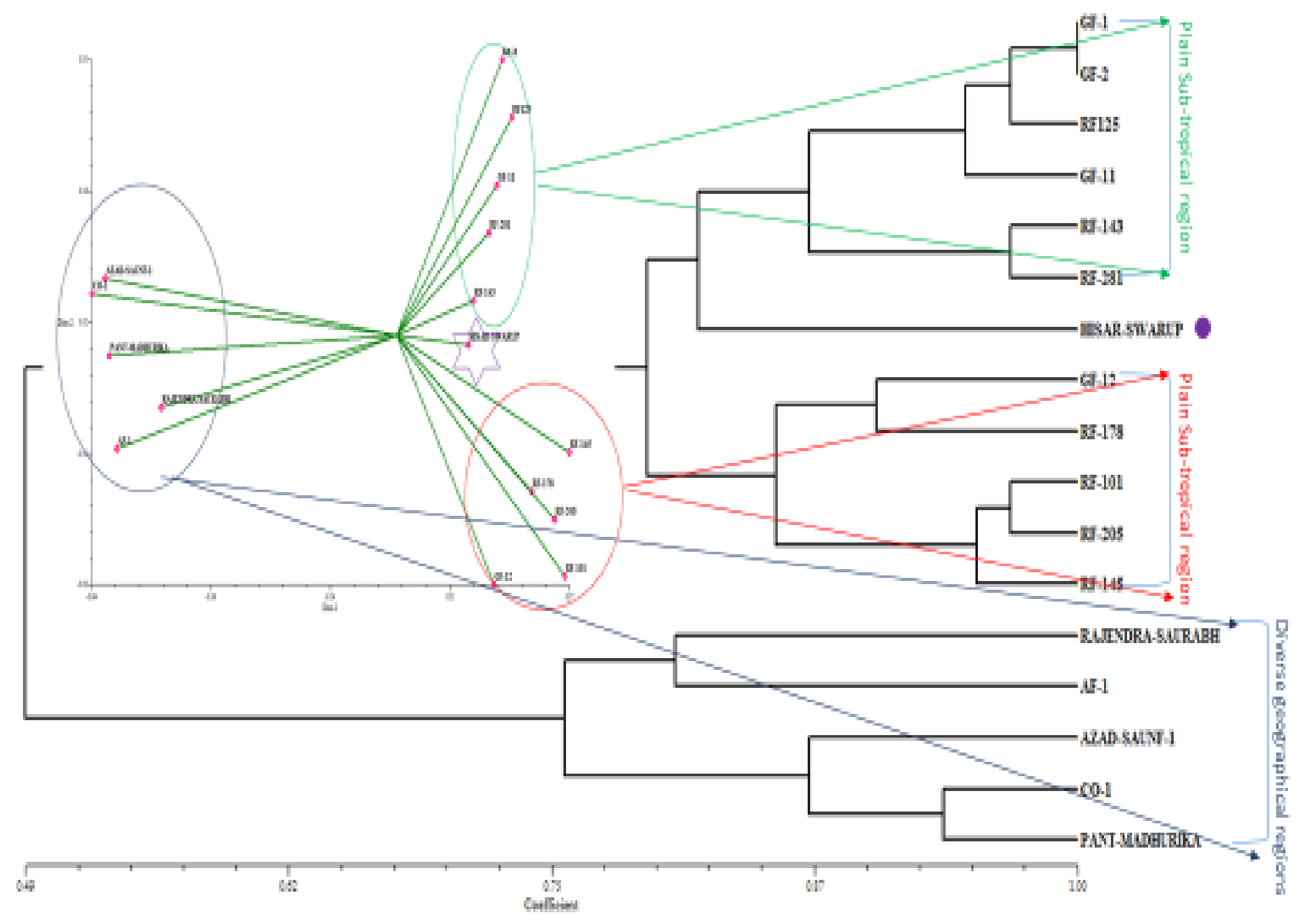


The ISSR cluster analysis of 17 fennel genotype showed that they were mainly divided into two major clusters at similarity coefficient of 0.40 (Figure 5). The cluster I contain five genotypes and out grouped from other at a similarity coefficient 0.73 . In this cluster all the genotypes belong to different geographical origin with vast molecular diversity. Similarly, cluster II have the remaining twelve genotypes. Similarly, Farajpour et al., (2012) also asses the molecular diversity using ISSR in medicinal plants Achillea millefolium. The analysis gave 16 PCs, out of which the first 10 PCs contributed $98.03 \%$ of the total variability of the analyzed genotypes. The first 5 PCs accounted for $82.91 \%$ of the total variability; the first 3 accounted for $69.74 \%$ of the variance, in which maximum variability was contributed by the first component $(42.65 \%)$, followed by the second (15.53\%) and third (11.56\%) components. Based on Mantel Zstatistics (Mantel, 1967), the correlation coefficient ( $r$ ) was estimated as 0.93. The $r$ value of 0.949 was considered a good fit of the UPGMA cluster pattern to ISSR data.

\section{Cumulative data analysis of RAPD and ISSR molecular marker}

Pairwise similarity among the genotypes ranged from 0.27 to 1.0 based on combined morphometric RAPD and ISSR. The highest similarity $(100 \%)$ was observed between the GF1 and GF2, whereas the lowest was observed between RF145 and AF-1. A dendrogram based on RAPD and ISSR clustered all 17 genotypes into 3 major clusters at similarity coefficient of 0.60 . Based on Mantel Z-statistics (Mantel, 1967), the correlation coefficient (r) was estimated as 0.93 . The $r$ value of 0.94 was considered a good fit of the UPGMA cluster pattern to the cumulative RAPD and ISSR data. The Mantel $\mathrm{Z}$ test also revealed moderate level of correlation between RAPD and ISSR data.
The matrix correlation coefficient $r$ (normalized Mantel statistic Z) was 0.66753, which shows the data is significant. The association amongst different genotypes were presented in the form of dendogram, the genotype which lay nearer to each other in dendogram are more similar to one another then those lying apart. The dendogram also showed the relative magnitude of resemblance among different genotypes of fennel used for current investigation.

\section{Unique bands in 17 fennel genotypes}

Some primers gave unique bands in specific fennel genotypes as shown in (Table 2). These primers produced specific DNA bands which distinguished one genotype from the rest. Primer OPB-07 generated a unique allele for Pant-madurika (Figure 1). Primers OPB11 generated a unique band for the CO-1. Similarly, ISSR primer UBC-810 generated a unique allele for Hisar-swarup (Figure 2).

In the present investigation, estimation of genetic variability to establish genetic relationships through RAPD and ISSR markers analyses among the fennel genotypes were successfully revealed. The RAPD and ISSR data generated from the 17 genotype were sufficient to provide inferences on genetic divergence and relationships. The RAPD and ISSR markers showed a high level of polymorphism). Jaccard's genetic similarity values of RAPD and ISSR also revealed a high level of genetic diversity through RAPD and ISSR markers, This high level of genetic diversity suggests its wide genetic base which is possibly due to accumulation of novel gene combinations by cross pollination. DNA fingerprinting is a routine method employed to study the extent of genetic diversity across a set of genotypes or cultivars and group them into specific categories. In conclusion, results indicate the presence of high genetic variability among the 
elite fennel genotypes. Characterization and assessment of diversity among the fennel genotypes have great significance in designing breeding strategies, both for qualitative and quantitative traits. By this study, we have successfully assessed the level of inter and intra-specific diversity relationship among different fennel genotypes. Results derived from this study would be highly useful in fennel breeding programs and may be used for further crop improvement using advance marker systems.

\section{Acknowledgement}

The authors gratefully acknowledge the Director, ICAR- National Research Centre on Seed Spices, Ajmer, Rajasthan for providing facility, support and cooperation during course of investigation.

\section{References}

Barwar, A., Sangwan, M.L., Kumar, S. and Ahlawat, S. 2008. Molecular diversity between Murrah and Bhadawari breeds of Indian buffalo using RAPD-PCR. Indian. J. Biotechnol. 7 491-495.

Choudhary, S., Jethra, G., Sharma, R. and Verma, A.K. 2017. Microsatellite in coriander: A cross species amplification within Apiaceae family. International Journal of Current Microbiology and Applied Sciences, 6(5): 2714-2721.

Choudhary, S., Jethra, G., Sharma, R., Tripathi, A., Mishra, J. and Pareek, D. 2016. Rapid and reliable method for high quality RNA isolation from major seed spices. Journal of Plant Development Sciences, 8(2): 79-82.

Choudhary, S., Meena, R.S., Singh, R., Vishal, M.K., Choudhary, V. and Panwar, A. 2013. Assessment of genetic diversity among Indian fenugreek (Trigonella foenum -graecum L.) varieties using morphological and
RAPD markers. Legume Research, 36(4): 289-298.

Choudhary, S., Meena, R.S., Singh, R., Vishal, M.K., Jethra, G., Saini, M. and Panwar, A. 2015. Analysis of diversity among cumin (Cuminum cyminum) cultivars using RAPD markers. Indian Journal of Agricultural Sciences, 85(3): 409-413.

Choudhary, S., Pereira, A., Basu, S. and Verma, A.K. 2017. Differential antioxidant composition and potential of some commonly used Indian spices. Journal of Agrisearch, 4:160-166.

DASD, 205-16. http://dasd.gov.in /images/kerala/Spices-

Area_and_Production_in_India.pdf

Doyle, J.J. and Doyle, J.L. 1990. Isolation of plant DNA from fresh tissue. Focus. 12: 13-15.

Duran, C., Appleby, N., Edwards, D. and Batley, J. 2009. Molecular Markers: Discovery, applications, data storage and visualization. Curr. Bioinfo., 4:1627.

El-Awadi, M.E., and Hassan, E.A. 2010. Physiological responses of fennel (Foeniculum Vulgare Mill) plants to some growth substances. Journal of American Science. 6:985-991.

Farajpour, M., Ebrahimi, M., Amiri, R., Golzari, R. and Sanjari, S. 2012. Assessment of molecular diversity in Achillea millefolium accessions from Iran using ISSR marker. Biochem Syst Ecol., 43: 73-79.

Godwin, I.D, Aitken, E.A.B. and Smith, L.W. 1997. Application of inter-simple sequence repeats (ISSR) markers to plant genetics. Electrophoresis, 18: 1524-1528.

Haouari, M. and Ferchichi, A. 2008. Study of molecular polymorphism of Artemisia herba-alba from Tunisia using ISSR markers. Afr. J. Biotechnol., 7(1): 4450 . 
Jaccard, P. 1908. Nouvelles recherches sur la distribution florale. Bull Soc Vaudoise C. Sci Nat 44: 223-270.

Mantel, N. 1967. The detection of disease clustering and a generalized regression approach. Cancer Res, 27(2) 209-220.

Mattagajasingh, I., Mukherjee, A.K. and Das, P. 2006. Genomic relations among 31 species of Mammillaria haworth (Cactaceae) using Random Amplified Polymorphic DNA. Z Naturforsch, 61: 583-591.

Pirseyedi, S.M., Valizadehghan, S., Mardi, M., Ghafari, M.H., Mahmodi, P., Zahravi, M., Zeinalabedini, M. and Khayam Nekoui, S.M. 2010. Isolation and characterization of novel microsatelite Markers in Pomegranate (Punica granatum L.). Int. J. Mol. Sci., 1: 2010-2016.

Rohlf, F.J. 1998. NTSYS-PC Numerical taxonomy and multivariate analysis system. Version 2.02e. EXETER Software, New York.

Roldán-Ruiz, I., Calsyn, E., Gilliland, T.J., Coll, R., Van Eijk, M.J.T. and De Loose, M. 2000. Estimating molecular conformity between related ryegrass (Lolium) varieties. 2. AFLP characterization. Mol. Breeding 6: 593602.

Saleha, Y.M.A. 2011. Investigation of the molecular toxicology of dill and fennel extracts and cyclophosphamide in male rats by RAPD-PCR assay. Journal of American Science, 7(9): 398-408.
Saravanaperumal, S.A. and Terza, A.L. 2012. Polyphenolics free DNA isolation and optimization of PCR RAPD for fennel (Foeniculum vulgare Mill.) from mature and young leaves. African Journal of Biotechnology, 11(35): 8622-8631.

Singh, S.K., Kakani, R.K., Meena, R.S., Pancholy, A., Pathak, R. and Raturi, A. 2012. Studies on genetic divergence among Indian varieties of a spice herb. Coriandrum sativum. Journal of Environmental Biology, 33: 781-789.

Soriano, J.M., Zuriaga, E., Rubio, P., Llacer, G., Infante, R., and Badenes, M.L. 2011. Development and characterization of microsatellite markers in pomegranate (Punica granatum L.). Mol Breding, 27: 19-128.

Sosinski, B. and Douches, D.S. 1996. Use of PCR based DNA amplification to fingerprint North American potato cultivars. Horticulture Science, 31: 130133.

Sun, K., Chen, W., Ma, R.J. and Chen, X. 2004. A study on the molecular diversity of subpopulations of Hipophae rhamnoides spp. Sinensis at Ziwuling, Gansu. Journal of Lanzhou University (Natural University), 40(3): 72-75.

Varshney, R.K., Chabane, K., Hendre, P.S., Aggarwal, R.K. and Graner, A. 2007. Comparative assessment of EST-SSR, EST-SNP and AFLP markers for evaluation of molecular diversity and conservation of molecular resources using wild, cultivated and elite barleys. Plant Sci., 173: 638-649.

\section{How to cite this article:}

Sharda Choudhary, Radheshyam Sharma, R.S. Meena and Arvind Kumar Verma. 2018. Molecular Diversity Analysis in Fennel (Foeniculum vulgare Mill) Genotypes and its Implications for Conservation and Crop Breeding. Int.J.Curr.Microbiol.App.Sci. 7(03): 794809. doi: https://doi.org/10.20546/ijcmas.2018.703.093 